\title{
NUMERICAL INVESTIGATION ON THE EFFECTS OF OBSTRUCTION AND SIDE RATIO ON NON-NEWTONIAN FLUID FLOW BEHAVIOR AROUND A RECTANGULAR BARRIER
}

\author{
Sara Noferesti ${ }^{1}$, Hassan Ghassemi ${ }^{2}$, Hashem Nowruzi ${ }^{3}$ \\ ${ }^{1,3}$ Mechanical Engineering Department, Chabahar Maritime and Marine University, Chabahar, Iran \\ ${ }^{2}$ Department of Maritime Engineering, Amirkabir University of Technology, Tehran, Iran \\ snoferesti1590@gmail.com,gasemi@aut.ac.ir,h.nowruzi@aut.ac.ir
}

Received: 20 January 2019; Accepted: 15 May 2019

\begin{abstract}
In this paper, the characteristics of the flow and forced heat transfer of power law non-Newtonian fluids that flow around a quadrilateral and rectangular cylinder that are located in a 2D channel are investigated by use of the finite volume method (FVM) in a steady state flow regime. To this accomplishment, in the constant temperature, the effects of a different obstruction ratio, aspect ratio and Reynolds number are investigated. The Reynolds number in the range $5 \leq \operatorname{Re} \leq 40$, the power index in the range $0.5 \leq \mathrm{n} \leq 1.4$, the aspect ratio in the range $0.5 \leq \mathrm{a} \leq 2$, and the obstruction ratio in the range $0.125 \leq \mathrm{b} \leq 0.5$ were selected. By surveying the drag coefficient profiles, it's concluded that as the obstruction ratio increases, the drag coefficient is increased, while an increase in the Reynolds number causes the lower drag coefficient. In addition, the drag coefficient is strongly increased by aspect ratio enhancements.
\end{abstract}

MSC 2010: $76 D 05$

Keywords: non-Newtonian fluids, heat transfer, finite volume method, laminar flow

NOMENCLATURE

\begin{tabular}{|l|l|l|l|}
\hline \multicolumn{2}{|l|}{ Latin Letters } & \multicolumn{2}{l|}{} \\
\hline $\mathrm{C}_{\mathrm{d}}$ & Drag coefficient & $\mathrm{I}_{2}$ & second inertia of the strain tensor \\
\hline $\mathrm{U}_{\max }$ & maximum speed & $T$ & absolute temperature \\
\hline $\mathrm{T}_{\text {in }}$ & uniform entered temperature & $\mathrm{k}$ & conduction coefficient \\
\hline $\mathrm{V}$ & vector velocity & $\mathrm{c}_{\mathrm{p}}$ & specific heat at constant pressure \\
\hline $\mathrm{u}$ & Cartesian velocity in x-direction & \multicolumn{4}{|l|}{ Greek Letters } \\
\hline $\mathrm{v}$ & Cartesian velocity in y-direction & $\mu$ & viscosity \\
\hline $\mathrm{w}$ & Cartesian velocity in z-direction & $\rho$ & density \\
\hline $\mathrm{F}$ & vector of body forces & $\sigma$ & stress tensor \\
\hline $\mathrm{p}$ & total isentropic pressure & $\tau_{\mathrm{ij}}$ & shear rate tensor \\
\hline $\mathrm{H}$ & Breadth of channel & $\varepsilon_{\mathrm{ij}}$ & strain rate tensor \\
\hline $\mathrm{m}$ & fluid concentration coefficient & $\alpha$ & aspect ratio \\
\hline $\mathrm{n}$ & power law factor & $\beta$ & obstruction ratio \\
\hline
\end{tabular}




\section{Introduction}

Until now, researchers have been very interested in studying the fluid flows around a cylinder with different cross sections such as circles, squares, elliptics, etc. The importance of this phenomena in the industry is due to the need for continuous information on the parameters of fluid flow such as drag and lift forces, wake characteristics, frequency of vortex effusion phenomenon, etc. Also, studying the effects of the parameters affecting the cylinder heat transfer rate with the surrounding fluid has great importance in the industry for cooling the electronic components, designing heat exchangers, designing equipment for heat processing of foodstuffs, etc. In addition, studying this subject will provide a good opportunity for researchers to increase their theoretical understanding of different flow phenomena. On the other hand, polymer and multiphase systems in food, polymeric and pharmaceutical industries generally have non-Newtonian behaviors, and despite the relatively high occurrence of this behavior in the industry, there are few studies on the nonNewtonian flow around a square cross-section cylinder. In recent years, many scholars have studied the flow and heat transfer in non-Newtonian fluids around square [1-7] and circular [7-10] cylinders, and a large amount of information from flow and heat transfer characteristics has been collected on these references. For example, Dhiman et al. [1] investigated the hydrodynamic and thermal parameters of a square cylinder enclosed in a two-dimensional channel and their aim was to investigate the effect of the Péclet number and of the Obstruction effect on flow and heat transfer. Nitin et al. [2] studied the effect of the Reynolds number and power index on a rectangular cylinder, and their purpose was to study the Prandtl number effect on the heat transfer characteristics. Dhiman [3] investigated the effect of the Reynolds number and the power factor and the Prandtl number on obstruction. Yoon et al. [4] studied the flow and heat transfer parameters of a square cylinder in a two-dimensional channel, and they investigated the effect of the angle of deviation. Mousavi et al. [5] studied the flow and heat transfer from a square cylinder in a two-dimensional channel by using the MRT-Lattice Boltzmann combination method. Their aim was to investigate the effect of the angle of deviation on the characteristics of flow and heat transfer. Aboueian et al. [6] studied the flow and heat transfer of a square cylinder enclosed in a two-dimensional channel. Their aim was to study the parameters of the power law factor, Reynolds number, angle of deviation in the constant Prandtl number and the constant obstruction ratio. Dulhani et al. [7] studied the flow and mixed heat transfer of a square cylinder enclosed in a two-dimensional channel. Their goal was to study the angle of impact and its effect on the flow and mixed heat transfer.

The overall convective heat transfer from smooth circular cylinders was studied by Morgan [8]. A numerical solution of the steady-state Navier-Stokes and energy equations around a horizontal cylinder at a low Reynold's number was presented [9]. Zdravkovich presented the application of the flow around circular cylinders $[10,11]$. Dhiman et al carried out the steady flow across a confined square cylinder [12]. 
A two dimensional steady flow of a power-law fluid past a square cylinder in a plane channel was presented by Gupta et al. [13]. Bouaziz et al. [14] predicted the flow and heat transfer of power-law fluids in a plane channel with a built-in heated square cylinder. Bhatti et al. [15-19] presented some analytical and computational methods solving different problems. They solved an analytical simulation of the head-on collision by means of a singular perturbation method.

Based on cited works, it can be noted that there is a lack of study on the effect of different obstruction ratio, aspect ratio and Reynolds number on the non-Newtonian fluid flow behaviour around the rectangular channel. Therefore, in the present paper, the characteristics of the flow and heat transfer of power law non-Newtonian fluids in the long rectangular cylinder are investigated by using FVM in a steady state flow regime. This paper is drawn as follows: Section 2 is described the geometry and statement of the problem. Mathematical formulations of the continuity, momentum and energy equations are explained in Section 3. The statement of the problem and validation solution are given in Sections 4 and 5, respectively. Section 6 presents the numerical results of the drag and flow field and the effect of the Nusselt number. Finally, a conclusion is given in Section 7.

\section{Geometry and problem statement}

We consider the non-Newtonian and incompressible fluid flows through the long channel around the square cylinder. This case is illustrated in Figure 1. The flow with the parabolic velocity profile by maximum speed $U_{\max }$ and the uniform temperature $T_{\text {in }}$ is entered into the channel. The channel inlet distance to the center of the cylinder is $\mathrm{Lu}$, and the length of the channel from the center of the cylinder to the output edge of the channel is $\mathrm{L}_{\mathrm{d}}$, and the distance from the lowest point of the channel to the center of the cylinder is $\mathrm{H}_{\mathrm{d}}$ and the distance from the center of the cylinder to the highest point of the channel is $\mathrm{H}_{t}$. The channel wall is also thermally insulated and the sides of the body enclosed in the channel are kept at a constant temperature of $T_{w}$. The purpose of this study is to investigate the flow and heat transfer of a laminar and non-Newtonian fluid flow numerically. Fluid properties are given in Table 1.

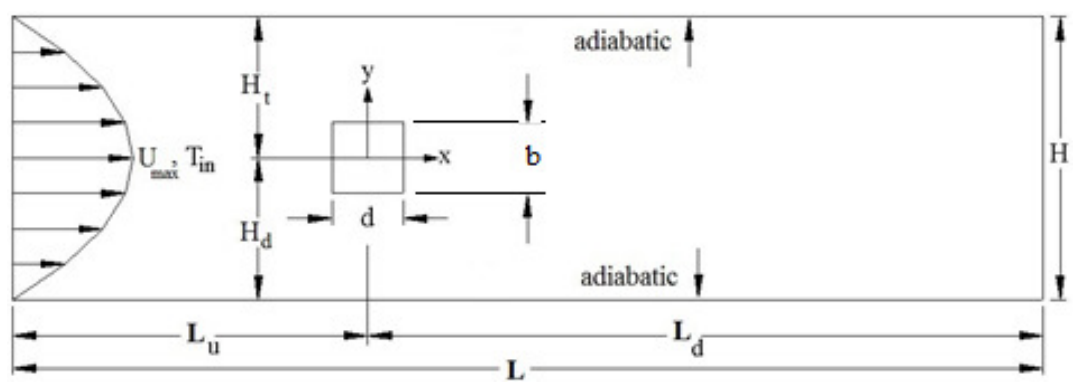

Fig. 1. Problem geometry 
Table 1. Physical properties of the fluid

\begin{tabular}{|c|c|c|c|c|}
\hline & $\rho\left[\mathrm{kg} / \mathrm{m}^{3}\right]$ & $\mathrm{k}[\mathrm{W} / \mathrm{m} \cdot \mathrm{K}]$ & $\mathrm{c}_{\mathrm{p}}[\mathrm{J} / \mathrm{kg} \cdot \mathrm{K}]$ & $\mathrm{m}\left[\mathrm{Pa} \cdot \mathrm{s}^{\mathrm{n}}\right]$ \\
\hline Fluid & 1200 & 298 & 149 & 60 \\
\hline
\end{tabular}

\section{Computational method}

\subsection{Mathematical formulation}

\section{- Continuity equation}

According to Eulerian's scheme, the mass conservation law or the Continuity equation is:

$$
\frac{\mathrm{D} \rho}{\mathrm{Dt}}+\rho \nabla \cdot \mathrm{V}=0
$$

here $\rho$ is the density, $\mathrm{V}$ is the vector velocity of the fluid (including the components $\mathrm{u}, \mathrm{v}$ and $\mathrm{w}$ in the Cartesian coordinate system) and $\frac{\mathrm{D}}{\mathrm{Dt}}$ is the total derivative operator, which is generally defined as follows:

$$
\frac{\mathrm{D} \varphi}{\mathrm{Dt}}=\frac{\partial \varphi}{\partial \mathrm{t}}+\mathrm{V} \cdot \nabla \varphi
$$

Equation (1) expresses more than the fact that mass is conserved. Since it is partial differential equation, the implication is that the velocity is continuous. For this reason, it is usually called the continuity equation. For incompressible fluid $\left(\frac{D \rho}{D t}=0\right)$ two-dimensional flow in the Cartesian coordinate system is as follows:

$$
\frac{\partial \mathrm{u}}{\partial \mathrm{x}}+\frac{\partial \mathrm{v}}{\partial \mathrm{y}}=0
$$

\section{- Momentum equations}

To balance forces in a controlled volume at a moment, using the Newton's second law, the momentum equation is:

$$
\rho \frac{\mathrm{DV}}{\mathrm{Dt}}=\nabla \cdot \sigma+\mathrm{F}
$$

where $\mathrm{F}$ and $\sigma$ represent the vector of body forces and the stress tensor respectively. The stress tensor is defined:

$$
\sigma=-p I+T
$$


where $\mathrm{p}, \mathrm{I}$, and $\mathrm{T}=\tau_{\mathrm{ij}}$ represent the total isentropic pressure of the characteristic tensor and the additional stress tensor or shear rate respectively.

By substituting equations (2) and (5) in equation (4), this equation will be as follows:

$$
\rho\left(\frac{\partial \mathrm{V}}{\partial \mathrm{t}}+\mathrm{V} \cdot \nabla \mathrm{V}\right)-\mathrm{F}=\nabla \cdot(-\mathrm{pI}+\mathrm{T})
$$

For incompressible non-Newtonian fluids, the additional stress tensor is defined as follows:

$$
\tau_{\mathrm{ij}}=2 \eta \varepsilon_{\mathrm{ij}}
$$

where $\varepsilon_{\mathrm{ij}}$ is the strain rate tensor and $\eta$ is the apparent viscosity. Regarding the two-dimensional problem in the Cartesian coordinate system, the strain rate tensor will be as follows:

$$
\varepsilon_{\mathrm{ij}}=\frac{1}{2}\left(\frac{\partial \mathrm{v}_{\mathrm{i}}}{\partial \mathrm{x}_{\mathrm{j}}}+\frac{\partial \mathrm{v}_{\mathrm{j}}}{\partial \mathrm{v}_{\mathrm{i}}}\right)
$$

According to the equation (8), the tensor components of the strain rate in the Cartesian coordinate system in the two-dimensional state will be as follows:

$$
\varepsilon_{\mathrm{xx}}=\frac{\partial \mathrm{u}}{\partial \mathrm{x}}, \quad \varepsilon_{\mathrm{yy}}=\frac{\partial \mathrm{v}}{\partial \mathrm{y}}, \quad \varepsilon_{\mathrm{xy}}=\varepsilon_{\mathrm{yx}}=\frac{1}{2}\left(\frac{\partial \mathrm{v}}{\partial \mathrm{x}}+\frac{\partial \mathrm{u}}{\partial \mathrm{y}}\right)
$$

The apparent viscosity is defined differently depending on the problem-solving model. In the power law model, the apparent viscosity $\eta$ is expressed by the following equation:

$$
\eta=m\left(\frac{I_{2}}{2}\right)^{(n-1) / 2}
$$

here $\mathrm{m}$ is the fluid concentration coefficient, $\mathrm{n}$ is the power law factor and $\mathrm{I}_{2}$ is the second inertia of the strain tensor. The concentration coefficient is equal to the average viscosity of the fluid. The second inertia of the strain tensor is defined as follows:

$$
\mathrm{I}_{2}=4\left(\varepsilon_{\mathrm{xx}}{ }^{2}+\varepsilon_{\mathrm{yy}}{ }^{2}+\varepsilon_{\mathrm{xy}}{ }^{2}+\varepsilon_{\mathrm{yx}}{ }^{2}\right)
$$

by substituting equations (9) and (11) in equations (2)-(10), the apparent viscosity for the power law fluid will be obtained:

$$
\eta=m\left[2\left(\frac{\partial u}{\partial x}\right)^{2}+2\left(\frac{\partial v}{\partial y}\right)^{2}+\left(\frac{\partial v}{\partial x}+\frac{\partial u}{\partial y}\right)^{2}\right]^{(n-1) / 2}
$$


So generally, for the power law model, equation (7) has following form:

$$
\tau_{\mathrm{ij}}=2 \mathrm{~m}\left[2\left(\frac{\partial \mathrm{u}}{\partial \mathrm{x}}\right)^{2}+2\left(\frac{\partial \mathrm{v}}{\partial \mathrm{y}}\right)^{2}+\left(\frac{\partial \mathrm{v}}{\partial \mathrm{x}}+\frac{\partial \mathrm{u}}{\partial \mathrm{y}}\right)^{2}\right]^{(\mathrm{n}-1) / 2} \varepsilon_{\mathrm{ij}}
$$

By simplifying these components according to the boundary conditions of the problem, the simplified form of the equation will be obtained. According to the problem geometry, and since the second component of velocity is zero, the equation (12) is expressed as follows:

$$
\begin{aligned}
& \tau_{\mathrm{xx}}=2 \eta \varepsilon_{\mathrm{xx}} \\
& \tau_{\mathrm{xx}}=2 \mathrm{~m}\left[2\left(\frac{\partial \mathrm{u}}{\partial \mathrm{x}}\right)^{2}+2\left(\frac{\partial \mathrm{v}}{\partial \mathrm{y}}\right)^{2}+\left(\frac{\partial \mathrm{v}}{\partial \mathrm{x}}+\frac{\partial \mathrm{u}}{\partial \mathrm{y}}\right)^{2}\right]^{(\mathrm{n}-1) / 2}\left(\frac{\partial \mathrm{u}}{\partial \mathrm{x}}\right) \\
& \tau_{\mathrm{yy}}=2 \eta \varepsilon_{\mathrm{yy}} \\
& \tau_{\mathrm{yy}}=2 \mathrm{~m}\left[2\left(\frac{\partial \mathrm{u}}{\partial \mathrm{x}}\right)^{2}+2\left(\frac{\partial \mathrm{v}}{\partial \mathrm{y}}\right)^{2}+\left(\frac{\partial \mathrm{v}}{\partial \mathrm{x}}+\frac{\partial \mathrm{u}}{\partial \mathrm{y}}\right)^{2}\right]^{(\mathrm{n}-1) / 2}\left(\frac{\partial \mathrm{v}}{\partial \mathrm{y}}\right) \\
& \tau_{\mathrm{xy}}=\tau_{\mathrm{yx}}=2 \eta \varepsilon_{\mathrm{xy}}=2 \mathrm{~m}\left[2\left(\frac{\partial \mathrm{u}}{\partial \mathrm{x}}\right)^{2}+2\left(\frac{\partial \mathrm{v}}{\partial \mathrm{y}}\right)^{2}+\left(\frac{\partial \mathrm{v}}{\partial \mathrm{x}}+\frac{\partial \mathrm{u}}{\partial \mathrm{y}}\right)^{2}\right]^{(\mathrm{n}-1) / 2}\left(\frac{1}{2}\left(\frac{\partial \mathrm{v}}{\partial \mathrm{x}}+\frac{\partial \mathrm{u}}{\partial \mathrm{y}}\right)\right) \\
& \eta=\mathrm{m}\left(\frac{\partial \mathrm{u}}{\partial \mathrm{y}}\right)^{\mathrm{n}-1}
\end{aligned}
$$

The strain rate is also simplified as follows:

$$
\varepsilon_{\mathrm{yx}}=\frac{1}{2}\left(\frac{\partial \mathrm{u}}{\partial \mathrm{y}}\right)
$$

In the end, according to equation (16), the additional stress equation in power law non-Newtonian fluid for the simple Couette flow in the xy plane is:

$$
\tau_{\mathrm{yx}}=\mathrm{m}\left(\frac{\partial \mathrm{u}}{\partial \mathrm{y}}\right)^{\mathrm{n}}
$$

Therefore, due to the two-dimensional problem in the Cartesian coordinate system, the momentum equations have the following form: 
Momentum equations in $\mathrm{x}$ direction:

$$
\frac{\partial u}{\partial t}+\rho\left(u \frac{\partial u}{\partial x}+v \frac{\partial u}{\partial y}\right)=-\frac{\partial p}{\partial x}+\frac{\partial \tau_{x x}}{\partial x}+\frac{\partial \tau_{y x}}{\partial y}
$$

Momentum equations in y direction:

$$
\frac{\partial v}{\partial t}+\rho\left(u \frac{\partial v}{\partial x}+v \frac{\partial v}{\partial y}\right)=-\frac{\partial p}{\partial y}+\frac{\partial \tau_{x y}}{\partial x}+\frac{\partial \tau_{y y}}{\partial y}
$$

where, $\tau_{\mathrm{ij}}$ is obtained from equations (14), (15) and (16).

\section{- Energy equation}

For an incompressible fluid with constant properties and in a $2 \mathrm{D}$ steady state flow, considering the viscous losses term, the first law of thermodynamics or the energy equation related to the temperature is:

$$
\frac{\partial \mathrm{T}}{\partial \mathrm{t}}+\mathrm{u} \frac{\partial \mathrm{T}}{\partial \mathrm{x}}+\mathrm{v} \frac{\partial \mathrm{T}}{\partial \mathrm{y}}=\frac{\mathrm{k}}{\rho \mathrm{c}_{\mathrm{p}}}\left(\frac{\partial^{2} \mathrm{~T}}{\partial \mathrm{x}^{2}}+\frac{\partial^{2} \mathrm{~T}}{\partial \mathrm{y}^{2}}\right)+\frac{1}{\rho \mathrm{c}_{\mathrm{p}}}\left[\tau_{\mathrm{xx}} \frac{\partial \mathrm{u}}{\partial \mathrm{x}}+\tau_{\mathrm{xy}}\left(\frac{\partial \mathrm{u}}{\partial \mathrm{y}}+\frac{\partial \mathrm{v}}{\partial \mathrm{x}}\right)+\tau_{\mathrm{yy}} \frac{\partial \mathrm{v}}{\partial \mathrm{y}}\right]
$$

here $\mathrm{T}$ is the absolute temperature, $\mathrm{k}$ is the conduction coefficient and $\mathrm{c}_{\mathrm{p}}$ is the specific heat at constant pressure. The second term on the right hand side of the equation is the viscous loss. By replacing the values of additional stresses which are gained from equations (9) and (11), the energy equation is expressed as:

$$
\frac{\partial \mathrm{T}}{\partial \mathrm{t}}+\mathrm{u} \frac{\partial \mathrm{T}}{\partial \mathrm{x}}+\mathrm{v} \frac{\partial \mathrm{T}}{\partial \mathrm{y}}=\frac{\mathrm{k}}{\rho \mathrm{c}_{\mathrm{p}}}\left(\frac{\partial^{2} \mathrm{~T}}{\partial \mathrm{x}^{2}}+\frac{\partial^{2} \mathrm{~T}}{\partial \mathrm{y}^{2}}\right)+\frac{\eta}{\rho \mathrm{c}_{\mathrm{p}}}\left[2\left(\frac{\partial \mathrm{u}}{\partial \mathrm{x}}\right)^{2}+\left(\frac{\partial \mathrm{u}}{\partial \mathrm{y}}+\frac{\partial \mathrm{v}}{\partial \mathrm{x}}\right)^{2}+2\left(\frac{\partial \mathrm{v}}{\partial \mathrm{y}}\right)^{2}\right]
$$

\subsection{Boundary condition}

\section{- Boundary condition in a channel inlet}

The speed at the channel inlet is assumed to be fully developed. Also, the fluid temperature at the inlet is:

$$
\mathrm{u}=\mathrm{U}_{\max }\left[1-\left|\frac{2 \mathrm{y}}{\mathrm{H}}\right|^{(\mathrm{n}+1) / \mathrm{n}}\right], \quad \mathrm{v}=0, \quad \mathrm{~T}=\mathrm{T}_{\mathrm{in}}
$$

here $-\mathrm{H} / 2 \leq \mathrm{y} \leq \mathrm{H} / 2$ and $\mathrm{U}_{\max }$ are the maximum speed at the input. 


\section{- Boundary condition of the upper and lower walls of channel}

The upper and lower walls of the channel are stationary and the no-slip condition is also confirmed. The walls are also thermally adiabatic:

$$
\mathrm{u}=0, \quad \mathrm{v}=0, \quad \frac{\partial \mathrm{T}}{\partial \mathrm{y}}=0
$$

\section{- Square barrier boundary condition}

The barrier is stationary in the channel and the no-slip condition is also presented and the barrier is in the constant temperature:

$$
\mathrm{u}=0, \quad \mathrm{v}=0, \quad \mathrm{~T}=\mathrm{T}_{\mathrm{w}}
$$

\section{- Boundary condition in channel outlet}

The flow in the output is assumed to be fully developed in terms of the velocity and temperature field. The physical interpretation of this choice is that the barrier inside the channel has no effect on the output stream. For this purpose, the output boundary should be sufficiently far away from the barrier to prevent any effect on the flow at the output:

$$
\frac{\partial \mathrm{u}}{\partial \mathrm{x}}=0, \quad \frac{\partial \mathrm{v}}{\partial \mathrm{x}}=0, \quad \frac{\partial \mathrm{T}}{\partial \mathrm{x}}=0
$$

\section{Statement of the problem}

The FVM has been used to solve the problem by using the Fluent CFD package. The SIMPLE algorithm was used for speed and pressure field coupling and the upwind second order algorithm was used for discretization of the governing equations. The convergence criterion was considered $10^{-6}$. The Reynolds number is defined as $\operatorname{Re}=\frac{\rho \mathrm{U}_{\max }^{2-n} b^{n}}{\mathrm{~m}}$ for a power law non-Newtonian fluid flow. The sides aspect ratio $(\alpha)$ is defined as the ratio of the horizontal side to the vertical side and the obstruction ratio $(\beta)$ defined as the vertical length of the barrier to the width of the channel.

\subsection{Study of computational domain of solution}

In this section, the mesh size or suitable mesh for grid generation of the problem will be determined. To find more accurate answers, the suitable mesh size has to be determined for the final solution to the problem. In this paper, the criteria of absolute error less than $1 \%$ is used for the selection of a proper mesh in $\mathrm{x}$ and directions. It is also notable that all the results presented here are for $\rho=1200 \mathrm{~kg} / \mathrm{m}^{3}$, 
$\mathrm{c}_{\mathrm{p}}=149 \mathrm{~J} / \mathrm{kg} \cdot \mathrm{K}$, Tin $=300 \mathrm{~K}, \mathrm{~T}_{\mathrm{w}}=313.42 \mathrm{~K}$. According to the research of Aboueian et al. [6], the values of $L_{u}$ and $L_{d}$ are 10 and $12 \mathrm{~m}$, respectively. The mesh sample pattern is available in Figure 2.

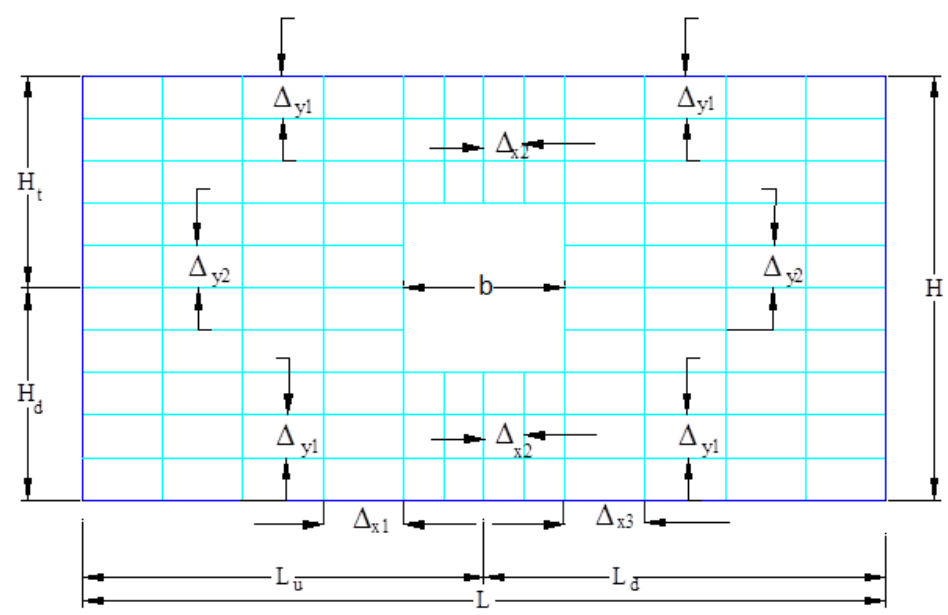

Fig. 2. The mesh scheme in a part of solution field

These areas include five types of mesh. For example, meshes used in the vicinity of the barrier and the channel walls are chosen smaller due to the significant values of the speed and temperature gradients in these zones. The length and height of the channel and the dimensions of the barrier and other parameters are shown in Figure 2. By using the grid compression method, Figure 2 was used to obtain an optimal grid. An optimal grid is also tabulated in Table 2. From Table 2, it is concluded that in grid No. 3 (G3), the drag coefficient error is less than $1 \%$, so the independence of the grid is proven.

Table 2. Finding optimal grid

\begin{tabular}{|c|c|c|c|c|c|c|c|}
\hline Grid & $\Delta \mathrm{x}_{1}$ & $\Delta \mathrm{x}_{2}$ & $\Delta \mathrm{x}_{3}$ & $\Delta \mathrm{y}_{1}$ & $\Delta \mathrm{y}_{2}$ & $\begin{array}{c}\text { Number of } \\
\text { Cells }\end{array}$ & $\mathrm{C}_{\mathrm{d}}$ \\
\hline $\mathrm{G} 1$ & 0.6 & 0.04 & 0.6 & 0.08 & 0.08 & 1259 & 1.5594 \\
\hline $\mathrm{G} 2$ & 0.3 & 0.02 & 0.3 & 0.04 & 0.04 & 4673 & 1.5847 \\
\hline G3 & 0.15 & 0.01 & 0.15 & 0.02 & 0.02 & 18344 & 1.5949 \\
\hline G4 & 0.075 & 0.005 & 0.075 & 0.01 & 0.01 & 72400 & 1.5949 \\
\hline
\end{tabular}

\section{Validation of numerical method}

To verify the validity of the numerical method used in this research, the following problem is solved analytically and numerically and the results are compared with each other. 


\subsection{Expression of the problem defined for validation}

As may be seen in Figure 3, water flow with the characteristics of $\rho=998.2 \mathrm{~kg} / \mathrm{m}^{3}$ and $\mu=0.001003 \mathrm{~kg} / \mathrm{m} \cdot \mathrm{s}$ is entered to a pipe with diameter $\mathrm{D}=0.1 \mathrm{~m}$ and length $\mathrm{L}=30 \mathrm{~m}$ at a speed of $=0.008 \mathrm{~m} / \mathrm{s}$ and it's exited at pressure $\mathrm{p}_{0}=0 \mathrm{~Pa}$. The goal is to compare the numerical solution with the analytical solution.

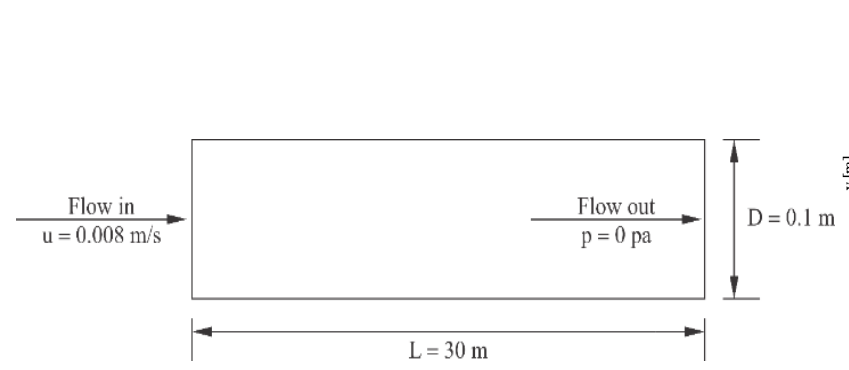

Fig. 4. Velocity profile on line $\mathrm{x}=17 \mathrm{~m}$

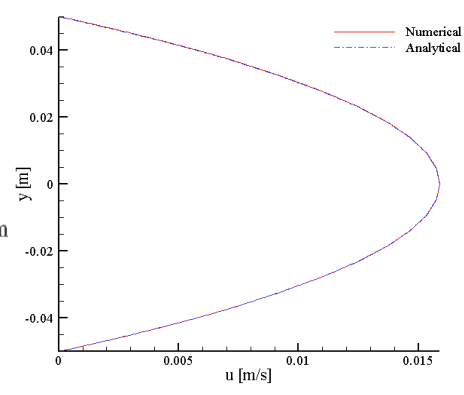

Fig. 3. Problem geometry

For validation, the axial velocity to channel width ratio has been plotted in Figure 4. The obtained average error shows good accordance between our CFD results with analytical data by less than $1 \%$ error.

\subsection{Problem solution validation}

To validate the solution, research has been done such as the following, which has been studied in various conditions. The results of this paper are in good agreement with the work of other researchers. The following results in Table 3 are obtained for the obstruction ratio $b=1 / 8$ and the side ratio $a=1$ (square object).

Table 3. Comparison of drag coefficient

\begin{tabular}{|c|c|c|c|c|c|c|}
\hline Re & $\begin{array}{c}\text { Power law } \\
\text { of fluid }(\mathrm{n})\end{array}$ & Present & $\begin{array}{c}\text { Aboueian } \\
\text { et al. [6] }\end{array}$ & $\begin{array}{c}\text { Dhiman et al. } \\
{[12]}\end{array}$ & $\begin{array}{c}\text { Gupta et al. } \\
{[13]}\end{array}$ & $\begin{array}{c}\text { Bouaziz et al. } \\
{[14]}\end{array}$ \\
\hline 5 & 0.5 & 6.536 & 6.682 & 6.355 & 6.338 & - \\
\hline & 1 & 5.482 & 5.975 & 5.849 & 5.549 & - \\
\hline & 1.4 & 5.122 & 5.320 & 5.038 & 4.948 & - \\
\hline 10 & 0.5 & 3.552 & 3.844 & 3.889 & 3.787 & - \\
\hline & 1 & 3.643 & 3.700 & 3.633 & 3.511 & - \\
\hline & 1.4 & 3.474 & 3.499 & 3.309 & 3.295 & - \\
\hline 20 & 0.5 & 3.343 & 2.374 & 2.437 & 2.5 & 2.465 \\
\hline & 1 & 2.460 & 2.486 & 2.442 & 2.448 & 2.372 \\
\hline & 1.4 & 2.486 & 2.494 & 2.374 & 2.399 & 2.545 \\
\hline 40 & 0.5 & 1.619 & 1.607 & 1.59 & 1.879 & 1.769 \\
\hline & 1 & 1.779 & 1.781 & 1.752 & 1.864 & 1.752 \\
\hline & 1.4 & 1.870 & 1.871 & 1.801 & 1.871 & 1.921 \\
\hline
\end{tabular}




\section{Results}

\subsection{Drag and flow field}

For a particular geometry, the total drag coefficient (even the compression and friction drag coefficients) is a function of the Reynolds number and the power index $n$. In the case of $n=1$, the fluid will be a Newtonian fluid, and the viscosity coefficient $(\mathrm{m})$ will be equal to the viscosity $(\mu)$ of the fluid. The total drag coefficient is obtained from the equation $\mathrm{C}_{\mathrm{d}}=2 \mathrm{~F}_{\mathrm{d}} / \rho \mathrm{\rho U}_{\text {max }}^{2}$, where $\mathrm{F}_{\mathrm{d}}$ is the drag force applied by the fluid on the body. The effect of power index (n) on the drag coefficient for condition $\alpha=1$ and $\beta=1 / 8$ is shown in Figure 5. According to Figure 5, the drag coefficient is reduced by increasing the Reynolds number. Aboueian et al. [6], in numerical solution of their research with 149 points of numerical data, presented an equation for the drag coefficient according to the parameters of the Reynolds number, the rotation angle of the body and the power index which for leading problem with zero rotation angle is: $1.2735+6.6188 \times \mathrm{Re}^{-1.0366}(\mathrm{n}+2.7268)^{1.6214}$. The comparison of the accuracy of this equation with our CFD data is shown in Figure 6. As it shown in Figure 6, this equation has a big error that is higher in lower Reynolds numbers.

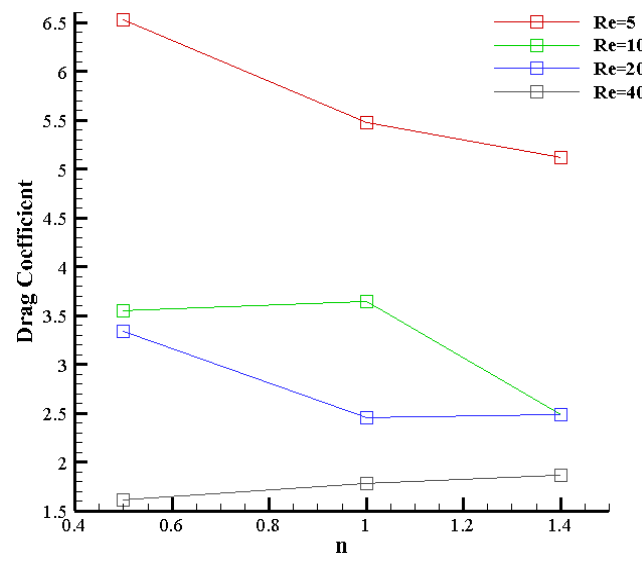

Fig. 5. The effect of power index (n) on drag coefficient for condition $\alpha=1$ and $\beta=1 / 8$

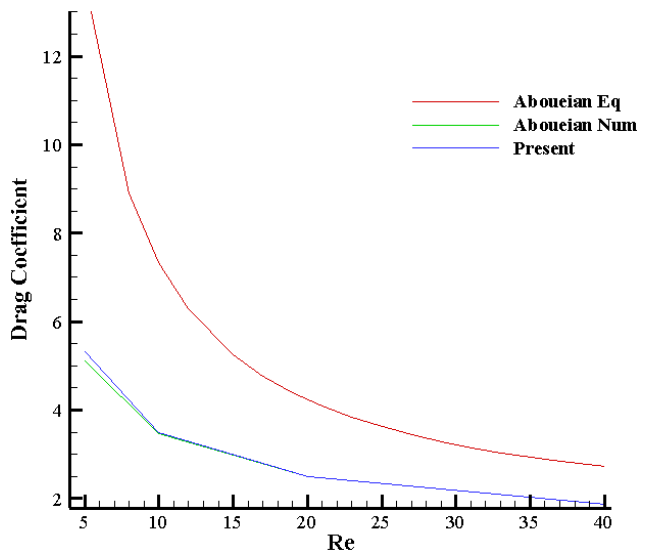

Fig. 6. Comparing the Aboueian equation with the results of the present study

The effect of the Reynolds number on the drag coefficient under condition $\alpha=1$, $\alpha=2$, and $\alpha=0.5$ for different obstruction ratios are plotted in Figures 7, 8 and 9, respectively. Increasing in the obstruction ratio increases the drag coefficient. But this increasing is limited and, in an obstruction ratio less than 0.5 , its effect is negligible. The effect of the Reynolds number on the drag coefficient in different sides ratios for condition $\beta=0.5$ is also presented in Figure 10. 


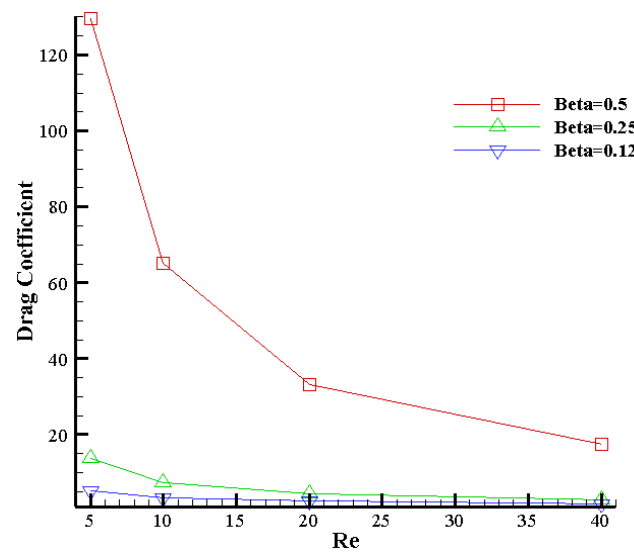

Fig. 7. The effect of Reynolds number on drag coefficient in different obstruction ratios for condition $\alpha=1$ and $n=1.4$

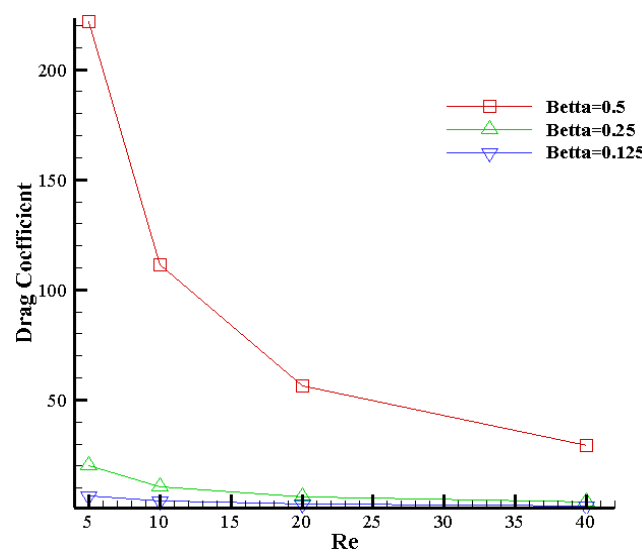

Fig. 9. The effect of Reynolds number on drag coefficient in different obstruction ratios for condition $\alpha=0.5$ and $n=1.4$

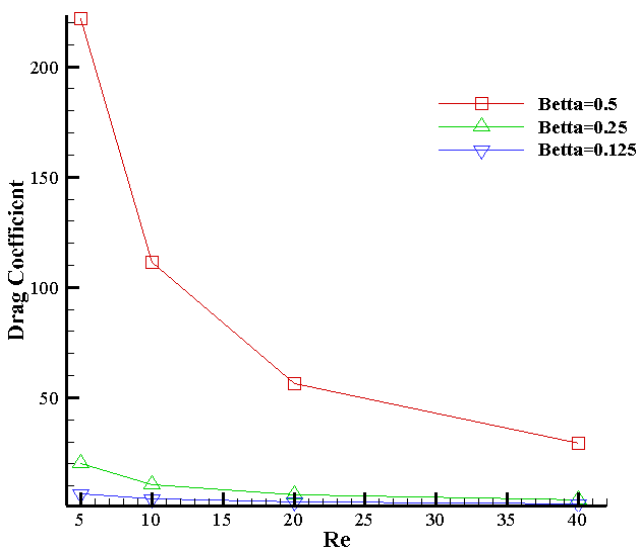

Fig. 8. The effect of Reynolds number on drag coefficient in different obstruction ratios for condition $\alpha=2$ and $n=1.4$

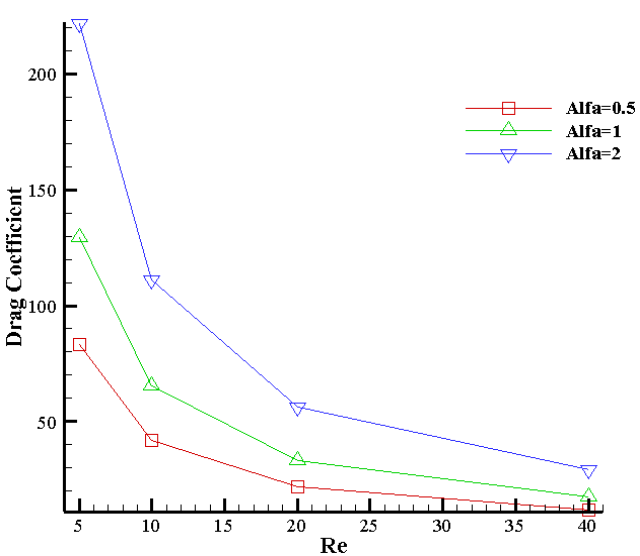

Fig. 10. The effect of Reynolds number on drag coefficient in different sides ratios for condition $\beta=0.5$ and $\mathrm{n}=1.4$

\subsection{Nusselt number}

The local Nusselt number is defined as $\mathrm{Nu}=\mathrm{hy} / \mathrm{k}$, which $\mathrm{y}$ is the characteristic length on the solid body's width and it's considered as a constant in all conditions. Nusselt number diagram on the barrier width in different Reynolds numbers and for conditions $\alpha=\beta=0.5$ and $n=1.4$ is presented in Figure 11. In Figure 11, the effect of the obstruction ratio on the Nusselt number is observed, which by increasing the obstruction ratio, the average Nusselt number increases. The Nusselt number diagram on the barrier width in obstruction ratios and for conditions $\operatorname{Re}=40$, $\alpha=0.5$ and $n=1.4$ is also shown in Figure 12. Figure 12 shows that with increasing Reynolds number, the vortexes behind the solid body increase and increase 
the heat transfer and increase the heat transfer coefficient. Also, on the above and below edges of the solid body, due to the destruction of the boundary layer, the Nusselt number has high value. In addition, the effects of the sides ratio on the Nusselt number is obvious in Figure 12, where as the sides ratio increases, the Nusselt number is decreased. Nusselt number diagram on the barrier width in different sides ratios and for conditions $\operatorname{Re}=40, \beta=0.5$ and $n=1$ is also presented in Figure 13.

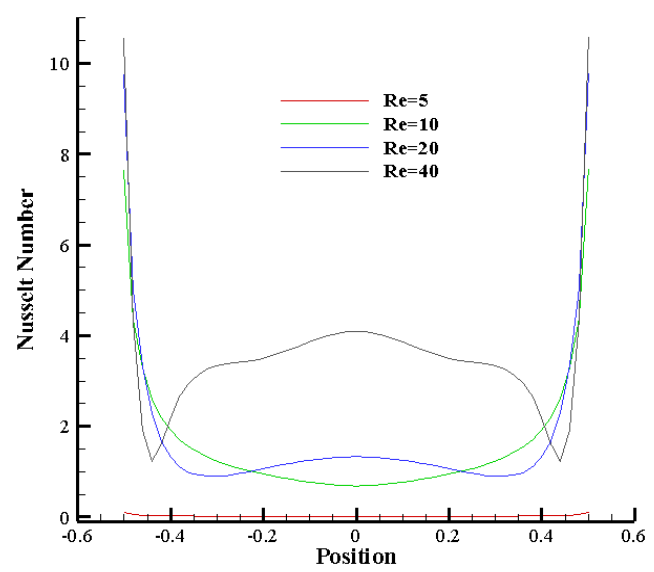

Fig. 11. Nusselt number diagram on the barrier width in different Reynolds numbers and for conditions $\alpha=\beta=0.5$ and $n=1.4$

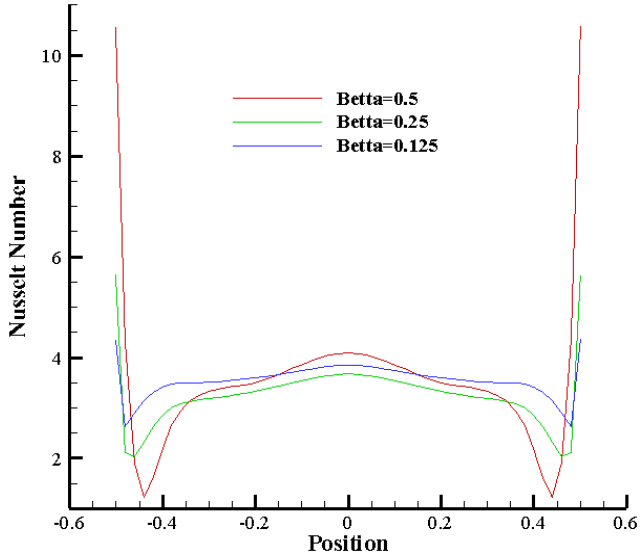

Fig. 12. Nusselt number diagram on the barrier width in obstruction ratios and for conditions $\operatorname{Re}=40, \alpha=0.5$ and $n=1.4$

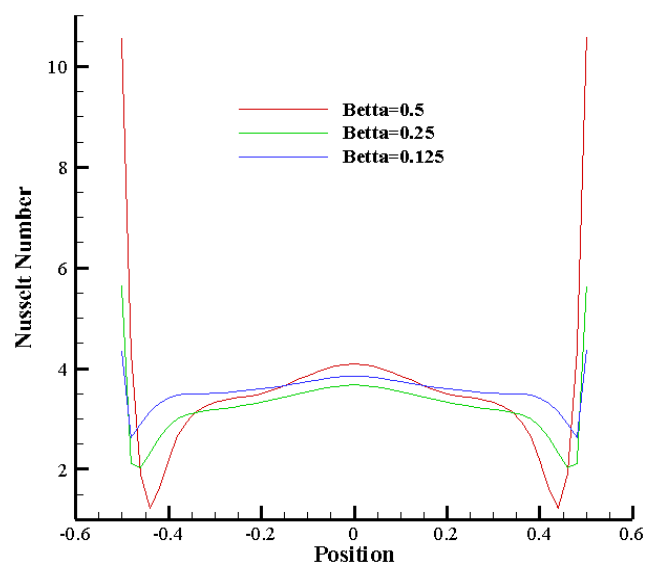

Fig. 13. Nusselt number diagram on the barrier width in different sides ratios and for conditions $\operatorname{Re}=40, \beta=0.5$ and $n=1$

\section{Conclusions}

In this current study, the effect of the obstruction ratio and the sides ratio of a rectangular cylinder enclosed in a $2 \mathrm{D}$ channel with a power law non-Newtonian 
fluid was numerically investigated. Comparison of our CFD results were validated with archival data. Drag coefficients were evaluated as a function of the Reynolds number, the obstruction ratio and sides ratio, and it was found that by increasing the Reynolds number, the drag coefficient is decreased for a specific fluid. However, for different fluids, the increase in the power index and the Reynolds number is cause of decreasing of drag coefficient. By investigating the effect of obstruction on the drag coefficient, we found that the drag coefficient is increased with increasing the obstruction ratio. The same result is obtained by increasing the sides ratio. Moreover, the Nusselt number increases on the back of the body due to the existence of vortexes but at the edges of the body, due to the destruction of the boundary layer, the Nusselt number is much higher. We also conclude that with increasing the Reynolds number, the Nusselt number increases and by increasing the obstruction ratio, the average Nusselt number is increased. It is also found that, as the sides ratio increases, the Nusselt number is decreased due to the increase in the growth of the boundary layer.

\section{References}

[1] Dhiman, A.K., Chhabra, R.P., \& Eswaran, V. (2005). Flow and heat transfer across a confined square cylinder in the steady flow regime: effect of Peclet number. International Journal of Heat and Mass Transfer, 48(21-22), 4598-4614.

[2] Nitin, S., \& Chhabra, R.P. (2005). Non-isothermal flow of a power law fluid past a rectangular obstacle (of aspect ratio $1 \times 2$ ) in a channel: drag and heat transfer. International Journal of Engineering Science, 43(8-9), 707-720.

[3] Dhiman, A.K. (2009). Heat transfer to power-law Dilatant fluids in a channel with a built-in square cylinder. International Journal of Thermal Sciences, 48(8), 1552-1563.

[4] Yoon, D.H., Yang, K.S., \& Choi, C.B. (2009). Heat transfer enhancement in channel flow using an inclined square cylinder. Journal of Heat Transfer, 131(7), 074503.

[5] Moussaoui, M.A., Jami, M., Mezrhab, A., \& Naji, H. (2010). MRT-lattice Boltzmann simulation of forced convection in a plane channel with an inclined square cylinder. International Journal of Thermal Sciences, 49(1), 131-142.

[6] Aboueian-Jahromi, J., Nezhad, A.H., \& Behzadmehr, A. (2011). Effects of inclination angle on the steady flow and heat transfer of power-law fluids around a heated inclined square cylinder in a plane channel. Journal of Non-Newtonian Fluid Mechanics, 166(23-24), 1406-1414.

[7] Dulhani, J.P., Sarkar, S., \& Dalal, A. (2014). Effect of angle of incidence on mixed convective wake dynamics and heat transfer past a square cylinder in cross flow at $\mathrm{Re}=100$. International Journal of Heat and Mass Transfer, 74, 319-332.

[8] Morgan, V.T. (1975). The overall convective heat transfer from smooth circular cylinders. In Advances in Heat Transfer (Vol. 11, pp. 199-264). Elsevier.

[9] Ahmad, R.A. (1996). Steady-state numerical solution of the Navier-Stokes and energy equations around a horizontal cylinder at moderate Reynolds numbers from 100 to 500. Heat Transfer Engineering, 17(1), 31-81.

[10] Zdravkovich, M.M. (1997). Flow Around Circular Cylinders: Fundamentals (Vol. 1). Oxford University Press.

[11] Zdravkovich, M.M. (2003). Flow Around Circular Cylinders: Applications (Vol. 2). Oxford University Press. 
[12] Dhiman, A.K., Chhabra, R.P., \& Eswaran, V. (2008). Steady flow across a confined square cylinder: Effects of power-law index and blockage ratio. Journal of Non-Newtonian Fluid Mechanics, 148(1-3), 141-150.

[13] Gupta, A.K., Sharma, A., Chhabra, R.P., \& Eswaran, V. (2003). Two-dimensional steady flow of a power-law fluid past a square cylinder in a plane channel: momentum and heat-transfer characteristics. Industrial \& Engineering Chemistry Research, 42(22), 5674-5686.

[14] Bouaziz, M., Kessentini, S., \& Turki, S. (2010). Numerical prediction of flow and heat transfer of power-law fluids in a plane channel with a built-in heated square cylinder. International Journal of Heat and Mass Transfer, 53(23-24), 5420-5429.

[15] Bhatti, M.M., \& Lu, D.Q. (2019). Analytical study of the head-on collision process between hydroelastic solitary waves in the presence of a uniform current. Symmetry, 11(3), 333.

[16] Bhatti, M.M., \& Lu, D.Q. (2018). Head-on collision between two hydroelastic solitary waves in shallow water. Qualitative Theory of Dynamical Systems, 17(1), 103-122.

[17] Bhatti, M.M., \& Rashidi, M.M. (2016). Effects of thermo-diffusion and thermal radiation on Williamson nanofluid over a porous shrinking/stretching sheet. Journal of Molecular Liquids, 221, 567-573.

[18] Bhatti, M., Abbas, T., Rashidi, M., Ali, M., \& Yang, Z. (2016). Entropy generation on MHD Eyring-Powell nanofluid through a permeable stretching surface. Entropy, 18(6), 224.

[19] Shahid, A., Zhou, Z., Hassan, M., \& Bhatti, M.M. (2018). Computational study of magnetized blood flow in the presence of Gyrotactic microorganisms propelled through a permeable capillary in a stretching motion. International Journal for Multiscale Computational Engineering, 16(4), 303-320. 